\title{
1 apologize, de Gisèle Vienne Ou as aporias d'O teatro pós-dramático de Hans-Thies Lehmann
}

\section{Carole Guidicelli}

Por razões várias, o nome de Gisèle Vienne merece ser incluido na lista elaborada por Hans-Thies Lehmann em 1999 para definir os contornos de uma vasta constelação de artistas que trabalham para criar obras "pós-dramáticas". $\mathrm{Na}$ verdade, esta jovem artista franco-austriaca, que se formou pela Escola Normal Superior das Artes da Marioneta (École Nationale Supérieure des Arts de la Marionette: ESNAM), de Charleville-Mézières (França), no mesmo ano em que foi publicado o livro Das Postdramatische Theater [0 teatro pós-dramático], desenvolve modos de trabalho de colaboração, em que a coreografia, o jogo do actor, os bonecos, a música e o texto convergem para criar obras polimórficas cujo significado nunca é fixo. Desde o seu primeiro espectáculo, Splendid's (2000), a partir de Jean Genet, esboçado na ESNAM, Gisèle Vienne explora - com o seu intérprete favorito Jonathan Capdevielle - a nossa relação perturbadora e transgressora com a morte e a beleza: impulsos sexuais e mórbidos do adolescente e/ou do assassino em série, presença erótica e perturbadora do boneco disponivel e submisso, beleza perfeita do corpo duma bailarina em movimento, beleza andrógina,

travestida, violada ou saqueada... É também por aí que os espectáculos de Gisèle Vienne se podem reportar ao "teatro pós-dramático" definido por Lehmann como um teatro de "corporalidade intensiva", onde "o corpo se absolutiza" (Lehmann 2002: 152): "0 amor expõe-se como presença sexual, a morte como SIDA, a beleza como perfeição do corpo" (ibid.), diz o teórico alemão.

No entanto, o quadro interpretativo proposto por 0 teatro pós-dramático, conjuntamente com as directrizes gerais que o fundamentam, poderia distorcer a perspectiva da análise e ocultar os profundos desafios do trabalho de Gisèle Vienne. É isto que me proponho demonstrar aqui, a partir da análise de uma de suas criações que, aparentemente, melhor se ajusta às categorias estéticas descritas por Lehmann.
I apologize ([Peço desculpa] 2004) representa uma viragem no trabalho de Gisèle Vienne porque este espectáculo marca o início de um diálogo artístico ininterrupto com o escritor americano Dennis Cooper. Os monólogos e os poemas de Cooper, proferidos pelo autor em voz off, estão intimamente ligados à música original de Peter Rehberg. Três intérpretes - 0 actor e performer Jonathan Capdevielle, a bailarina Anja Röttgerkamp e o cantor, designer e artista performer Jean-Luc Verna desenham de modo muito coreográfico poses e movimentos que criam diferentes configurações cénicas, o que thes permite experimentar diferentes cenários. Gisèle Vienne explica o princípio que está na base do espectáculo:

\footnotetext{
lapologize parte da reconstituição de um acidente. Esta reconstituição produz várias versões do acontecimento, a fim de identificar a realidade. Diferentes entre si, elas têm um estatuto confuso entre encenação de um acontecimento real e encenação duma fantasia, gerando a estrutura da peça: uma reflexão sobre a realidade e as suas hipotéticas representações. Estas diferentes versões, encenadas por um jovem que representa um homem, uma mulher, icones ao mesmo tempo rock e barrocos, e cerca de vinte adolescentes de cerca de doze anos sob a forma de bonecos articulados, vão gradualmente instalando a confusão na percepção do real, dominio da imprecisão, da subjectividade, cujas lacunas serão preenchidas pelas nossas fantasias.
}

Sinais pós-dramáticos e estrutura acústica Hans-Thies Lehmann caracteriza o teatro pós-dramático como um "teatro concreto" no sentido de o espectáculo se apresentar ao público como "um trabalho concreto sobre o espaço, o tempo, a fisicalidade, a cor, o som e o movimento" (Lehman 2002: 155). Ao fazer isso, apoia-se, segundo Lehmann, num jogo com o real que o afasta ao mesmo tempo da mimese e da ficção. Estas características estão de facto bem presentes em I apologize. 
Em primeiro lugar, pode notar-se que a cenografia do espectáculo não remete para nenhum lugar definido. Apenas sobressai o chão pela sua brancura lisa. Torna-se, de algum modo, neutro, assemelhando-se a uma página em branco, onde se agenciam os elementos que o intérprete principal, Jonathan Capdevielle, traz à cena, movimenta ou guarda: caixas de madeira com bonecos que figuram raparigas adolescentes de tamanho humano e com uniformes da escola, algumas cadeiras e uma série de adereços (uma pistola, uma máscara de monstro em látex uma garrafa de sangue a fingir...). 0 espaço organiza-se assim diante dos nossos olhos, de acordo com dispositivos com os quais Jonathan Capdevielle assume diferentes papéis: o de um director de cena que prepara cuidadosamente o cenário, colocando com precisão ou ajustando a postura de cada uma das bonecas; o de um observador por detrás da cena composta por aqueles simulacros de jovens raparigas; o de uma personagem que, por vezes, assume o mesmo estatuto, fazendo delas as suas parceiras de jogo numa relação que apresenta todos os sinais de uma cumplicidade ou até mesmo de uma amizade, enquanto outras vezes se transforma no seu agressor (e, portanto, confere-lhes o estatuto de seres humanos), outras vezes ainda age sobre elas sem qualquer respeito, devolvendo-as assim à sua passividade de simples bonecas.

Tal como o espaço, também a aç̧ão cénica e o jogo do actor são desconstruidos quase com a mesma rapidez com que são realizados. Nos primeiros minutos do espectáculo, o espectador vê um jovem banal, com jeans e uma camisola com capuz (Jonathan Capdevielle), percorrer o espaço cénico e movimentar as caixas numa espécie de não actuação; ele sai mesmo de cena pouco tempo depois de ter entrado: o espectador não pode deixar de pensar, naquele exacto instante, que foi um falso começo, um ajuste técnico... Depois Jonathan Capdevielle regressa ao espaço cénico e aos poucos o público começa a perceber que a colocação dos objectos é o centro da acção do espectáculo. Assim, o real aflora, no começo de I apologize, apenas quando o espectador está disposto a prestar-se ao jogo da convenção teatral e a deixar-se envolver numa eventual ficção. Não só o início deste espectáculo se atrasa mas, ainda por cima, não corresponde a uma verdadeira representação. Na verdade, I apologize apresenta-se como - para utilizar algumas importantes características do teatro pós-dramático assinaladas por Lehmann - uma forma de performance em que o processo de produção de uma acção física ("o fazer no real", ibid.: 165) prevalece sobre a sua representação, ou em que "a produção de acontecimentos de excepção" ou pelo menos de "instantes de desvio" (ibid:: 166) esvaziam a mimese e a fiç̧ão.
Esses momentos ou instantes surgem inesperadamente sem que o espectador consiga relacioná-los com uma acção de conjunto ou com o desenvolvimento lógico das fases de uma história. Por exemplo, a entrada em cena da bailarina (Anja Röttgerkamp), com peruca castanha, mini-saia e saltos de agulha pretos, não desencadeia nenhuma reacção por parte de Jonathan Capdevielle. Os movimentos de dança, que ela executa - de um virtuosismo corporal muito belo - não atraem os olhares do jovem, totalmente concentrado na disposição das caixas e na preparação de uma outra sequência de reconstituição. Em seguida, os dois intérpretes evoluem na cena de acordo com ritmos e códigos totalmente opostos. A expectativa - mais ou menos forte - do espectador em relação a uma qualquer cena em que contracenassem este jovem e esta "mulher fatal", que desenha movimentos muito bonitos e quase de contorcionista, é completamente defraudada. Pelo contrário, a entrada em cena de JeanLuc Verna, um ícone do rock cheio de tatuagens e vestido de preto, desencadeia uma cena erótica um tanto mórbida: deita-se no chão, virado para o público, colocando a cabeça exactamente na poça de sangue a fingir que Jonathan Capdevielle despejou no meio do palco uns momentos antes. Revista os bolsos de Jean-Luc Verna, pega um tubo de batom com que lhe pinta os lábios antes de Ihe dar um verdadeiro beijo lânguido de vários minutos.

Na maioria das vezes, as acções cénicas dos três intérpretes parecem mais cruzar-se ou justapor-se do que seguir uma lógica específica. Mesmo entre os gestos executados por cada artista, eventuais ligações com um mínimo de lógica entre causa e efeito são, por vezes, inexistentes. Um exemplo particularmente significativo: Jonathan Capdevielle espalha repetidamente "sangue" no chão enquanto se ouve o som de um disparo do revólver ou ainda quando empunha a arma para de facto atirar só muito mais tarde. Os signos teatrais, entendidos no seu sentido mais lato (elementos musicais, textuais, coreográficos, cenográficos...), não são hierarquizados nem participam na escrita do espectáculo de modo simultâneo, de acordo com o método da "parataxe". Como escreve Hans-Thies Lehmann:

Se nos questionamos sobre a intenção e os efeitos de simultaneidade então podemos verificar que o "parcelamento da percepção" se torna aqui uma experiência incontornável. [...] [P]erante o que é proposto em simultâneo, a alternativa muita vezes persiste: trata-se de uma verdadeira conexão "lógica", ou apenas de uma "simultaneidade" exterior? Estabelece-se uma dupla ligação sistemática: ao mesmo tempo, é preciso concentrar-se no pormenor concreto e ter também a percepção da totalidade. A parataxe e a simultaneidade levam a que o ideal estético clássico de uma coesão orgânica dos elementos do artefacto se torne obsoleto. (Ibid.: 138) 


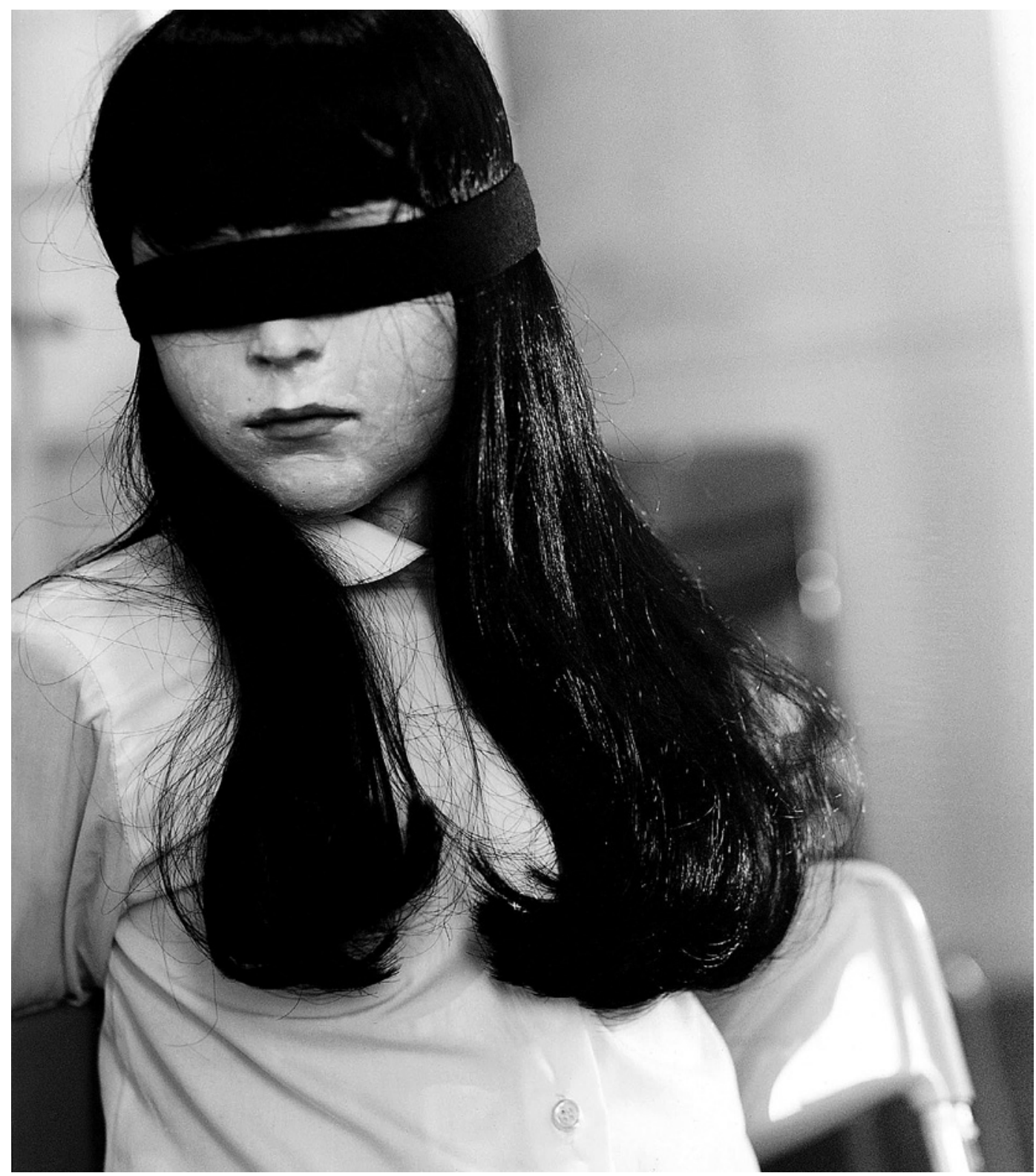

lapologize,

textos de Dennis Cooper,

enc. Gisèle Vienne,

DACM, 2004,

fot. Philippe Munda

- DACM.

Há, portanto, uma forma de organização dos elementos nos espectáculos de Gisèle Vienne, mas essa forma corresponde ao que Lehmann diz ser "pôr em música" (ibid.: 143), significando com isso que a linguagem teatral adoptaria os princípios da composição musical. Se as intervenções musicais inesperadas de Peter Rehberg criam evidentes rupturas estéticas e rítmicas, Gisèle Vienne também tira partido da marcação rítmica dos corpos: ritmo do andar rápido ou mais lento de Jonathan Capdevielle, conforme ele se movimenta para observar ou para organizar a cena, se anda em pé ou de quatro patas, se tem o rosto destapado ou usa uma máscara de monstro em látex, se tenta assustar ou atacar os seus companheiros de cena, ou se, finalmente, se enche de ânimo para beijar ou estrangular. Os corpos podem encontrar-se, transmitir um ritmo (o dos movimentos da dança que Anja transmite a Jean-Luc Verna, que, por sua vez, Ihe responde como em espelho), ou podem imobilizar-se numa determinada posição ou deixar-se cair, um de cada vez ou os dois ao mesmo tempo. Além disso, a repetição de certas acções com variantes (entornar sangue a fingir no chão, retirar as bonecas das caixas e depois guardá-las, tirar um batom do bolso de Jean-Luc Verna para o colocar ao lado dele...), o regresso de certos objectos e a retomada de certos motivos permitem identificar no espectáculo uma espécie de "estrutura acústica" (ibid:: 137).

No entanto, a existência de uma tal estrutura não seria suficiente, de acordo com Lehmann, para a criação de uma "totalidade" (ibid.), no sentido de um sistema de signos orientados para a comunicação de um sentido, para a resolução de um enigma. Lehmann vê neste "abandono da totalidade" o sintoma de um vazio de sentido caracteristico dos espectáculos pós-dramáticos. Este tipo de espectáculo na verdade não pediria ao espectador mais do que uma atenção flutuante face à proliferação de signos teatrais que Ihe chegariam sem que ele tivesse a capacidade de os hierarquizar ou de perceber neles uma qualquer estrutura narrativa. 0 processo seria, segundo Lehmann, o de desorientar o espectador, ou seja, de o exasperar: "a densidade desconcertante provoca uma sensação de caos, de insuficiência, de desnorteamento, de tristeza e de horror vacui" (ibid.: 143). 
lapologize

textos de Dennis Cooper,

enc. Gisèle Vienne,

DACM, 2004,

fot. Mathilde Darel

- DACM.

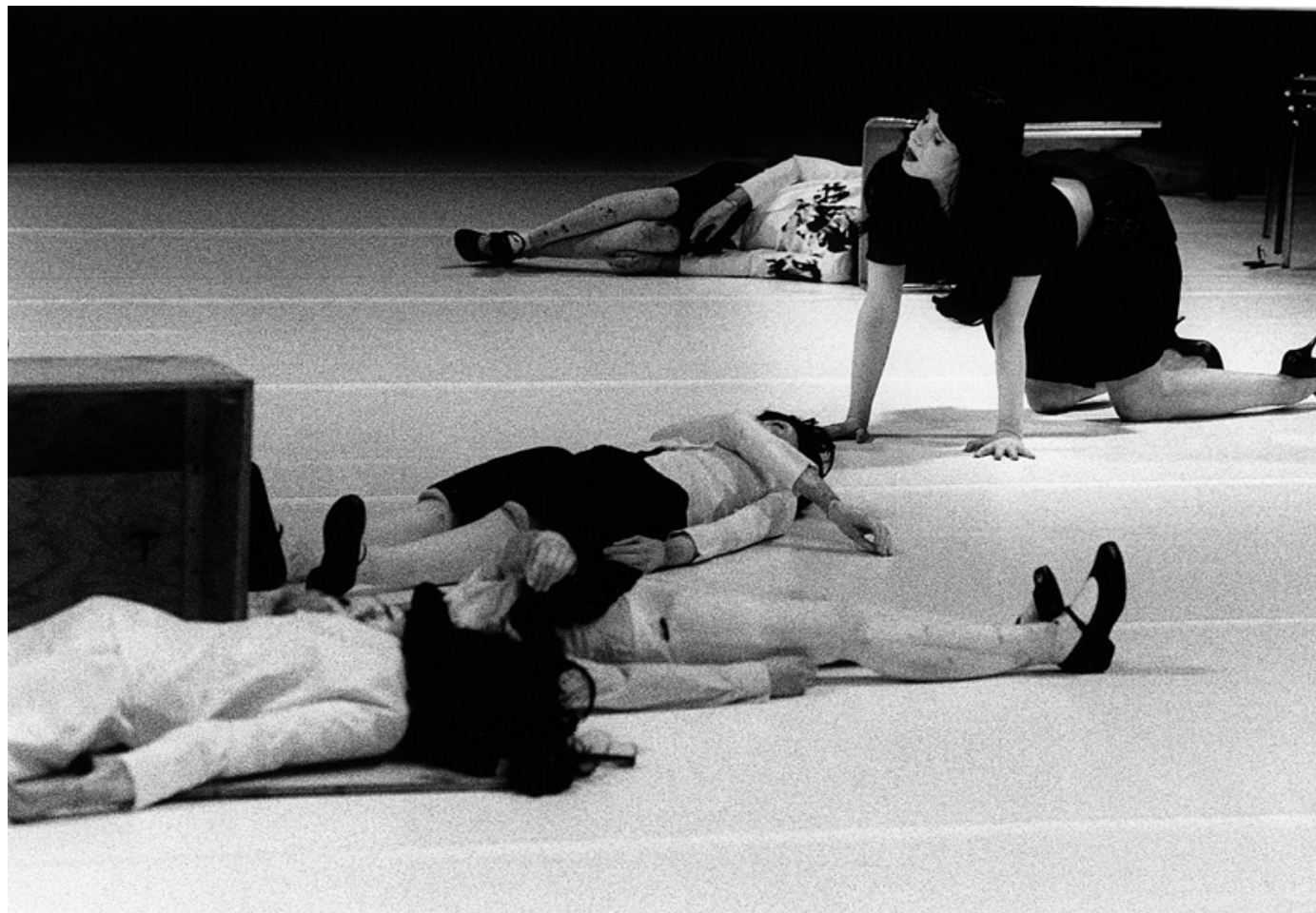

É aqui, parece-me, que o quadro interpretativo proposto por 0 teatro pós-dramático coloca problemas: a falta de uma narrativa de conjunto não leva necessariamente ao abandono de toda a narratividade e a acção representada em / apologize não deverá ser confundida com um caos vazio de sentido.

\section{Persistência do narrativo e lugar do espectador} Há, de facto, alguém que dirige o jogo cénico: Jonathan Capdevielle, que se esforça por desfazer as situações logo que elas surgem, como acontece logo com a primeira.

Depois de ter trazido, de fora de cena para o palco, uma boneca que ele senta numa das caixas à direita, e, a seguir uma cadeira que the permite instalar uma segunda boneca que estava no chão enrolada num cobertor, o actor sai de cena. 0 público ouve, vindo dos bastidores, o som de passos apressados associados a uma respiração cada vez mais ofegante. 0 jovem, que se tornou um cão feroz, desata a correr e atira-se para cima de uma das bonecas para lhe abocanhar a garganta. Mas, quando o público percebe a situação, ele pára de repente, endireita-se para observar a boneca antes de a pegar nos braços para criar outra mini cena. Desta vez, esta boneca - uma jovem com olhos vendados - é deitada no chão, de encontro ao canto de uma das caixas, a cabeça numa poça de "sangue" que Jonathan acabara de espalhar no chão, sobre as roupas da boneca e no bordo da caixa.

Deve também notar-se que as sequências do espectáculo não são apenas identificáveis em função das situações / cenas ou das entradas e saídas de um ou outro intérprete. São também - elas próprias - elementos visuais, sonoros ou rítmicos utilizados para delimitar os diferentes momentos de I apologize. Por exemplo, Jonathan

Capdevielle, depois de limpar as mãos cheias de sangue, senta-se no proscénio e observa as duas bonecas que arrumara em cena. Uma música original de Peter Rehberg "ocupa" o espaço enquanto se ouve a voz de Dennis Cooper a dizer um longo monólogo poético. E contudo, nem a palavra nem a música servem para esclarecer o que acontece no palco, mesmo que o espectador seja livre de pensar que, naquele momento, se trata da voz interior de Jonathan Capdevielle.

Todavia, como vimos, a ausência de ligações lógicas entre as acções de lapologize não impede que surjam situações bem definidas, evocando conflitos violentos (ou não) e apelando a uma certa identificação por parte do espectador: o jovem que veste a máscara de monstro em látex e que se diverte a assustar as suas colegas, o que assume a posição do melhor amigo e confidente, o que de repente se torna agressivo e quer bater, morder ou matar toda a gente, o que transborda de energia sexual e segue o seu impulso beijando ora uma rapariga ora um rapaz... Além disso a forma teatral concita outras formas de espectáculo, sobretudo de géneros mais populares, como o filme gore (com o monstro assassino que Jonathan Capdevielle se diverte a interpretar), mas também o número de drag queen com Jean-Luc Verna vestido de estrela rock a imitar Anja Rotterkamp...

Mais do que personagens, são representações icónicas, elas próprias carregadas de uma dimensão narrativa: vêm das cenas dos nossos desejos e dos nossos fantasmas. Considero que a metamorfose que Jean-Luc Verna efectua à frente dos nossos olhos é o emblema do espectáculo. Um longo black out, em que se ouve uma composição musical de Rehberg, prepara o espectador para o que irá presenciar. Jean-Luc Verna está outra vez deitado no chão virado para nós. Jonathan Capdevielle remexe nos bolsos para retirar batom, eye liner e um pequeno espelho, e coloca-os à sua frente. Jean-Luc Verna levanta-se, pintase, despe-se totalmente, revelando assim aos nossos olhos todo o seu corpo tatuado. A seguir veste uma combinação preta vaporosa, uma peruca castanha e saltos altos. Entretanto, sempre com a música como fundo, Jonathan Capdevielle coloca as caixas em fila, a fim de criar um 


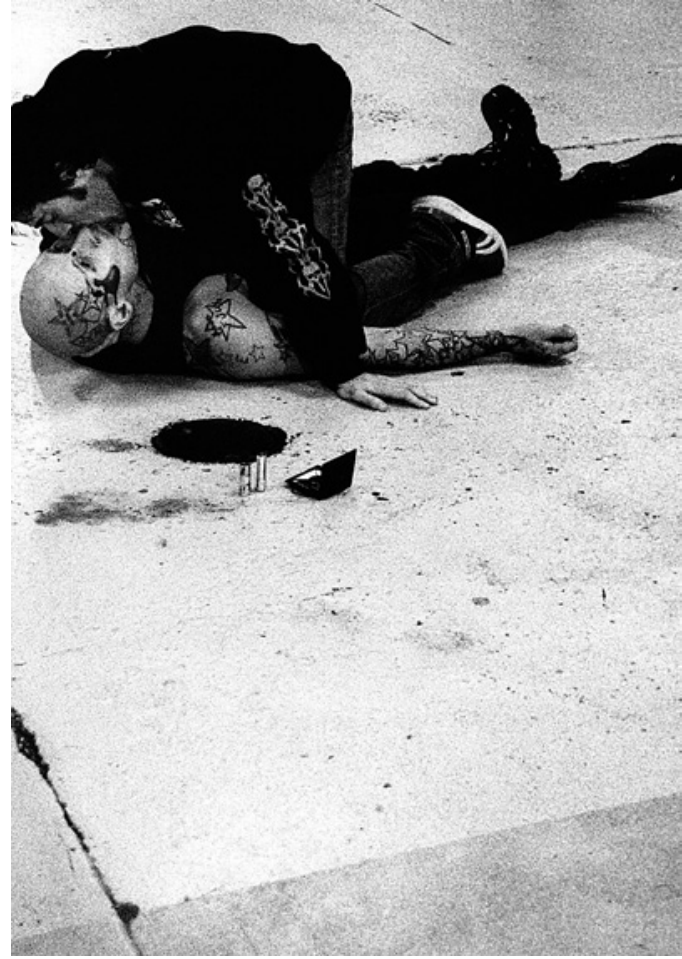

longo pódio. Por fim, a estrela pode fazer o seu espectáculo. 0 que nos conta esta cena? Ela mostra-nos que a beleza e a feminilidade são construções culturais e fantasmáticas que circulam através de códigos - e convenções - que podem ser contornados, desconstruídos ou recriados à vontade. E mostra-nos ainda os corpos - do homem ou da mulher - transformados em ícones, conjuntos de signos destinados a tornarem-se os suportes das nossas fantasias.

Nesta perspectiva, entende-se facilmente que Gisèle Vienne atribua ao espectador um papel activo de acordo com duas modalidades essenciais. Por um lado, ele é estimulado a questionar-se sobre o que vê e a modificar as hipóteses que constrói sobre o que realmente aconteceu entre o jovem e as jovens raparigas / bonecas, e depois, o que aconteceu entre este, a jovem morena que dança (Anja Röttgerkamp) e o homem tatuado com a aparência de estrela rock (Jean-Luc Verna). Por outro lado, o espectador, quando não lhe é dada uma história, é convidado a inventar uma, ele próprio, a partir das lacunas do que the é mostrado, deixando caminho livre às suas projecções fantasmáticas a partir das figuras icónicas que aparecem em cena, bem como dos cenários - às vezes eróticos e outras vezes mórbidos - que lhe são apresentados.

Portanto, os diferentes modos de escrita de lapologize também fazem surgir outros modos de agenciamento da narrativa que reenviam quer à cultura popular de Gisèle Vienne (a série televisiva Twin Peaks, ou ainda os filmes de terror), quer à sua leitura assídua de Alain RobbeGrillet. Em Pour un nouveau roman [Para um novo romance], o escritor recorda que

"[...] não se deve assimilar a busca de novas estruturas da narrativa a uma supressão pura e simples de todo o acontecimento, de toda a paixão, de toda a aventura. [...]. Eu sublinharia que os romances Les gommes (As borrachas, 1953) ou Le voyeur (O voyeur, 1955) têm ambos um enredo, uma 'acção' facilmente discernivel, enriquecida lapologize, textos de Dennis Cooper enc. Gisèle Vienne, DACM, 2004 (Jonathan Capdevielle e Jean-Luc Verna), fot. Philippe Munda - DACM.

com elementos geralmente considerados dramáticos. Se inicialmente pareceram menos organizados a alguns leitores, não será pura e simplesmente porque o movimento da escrita é ai mais importante do que as paixões e os crimes?" (Robbe-Grillet 1963: 32)

De modo semelhante, o efeito de desconstrução peculiar de I apologize não significa uma rejeição "de todo o acontecimento, de toda a paixão, de toda a aventura", nem as acções, que aí se encandeiam, convocam, de modo algum, a atenção errática evocada por Lehmann. Cada motivo narrativo é dado aqui em toda a sua força fantasmática: o sangue derramado que se limpa ou em que se chafurda; a jovem passiva, oferecida, prisioneira de olhos vendados, ou a dançarina desarticulada que se cobiça, beija, levanta, pousa no chão ou estrangula; a morte infligida, aceite ou provocada por acidente, a agressão, o homicídio ou o massacre colectivo; a atracção sexual irreprimivel que faz de cada um ora um animal (ou um monstro), ora uma vítima (ou um mártir)... Devido a essa carga instintiva, o espectador, perturbado e preocupado ao mesmo tempo, não deixou de imaginar ligações narrativas entre as várias acções cénicas que acontecem diante dos seus olhos, os textos muitas vezes explícitos de Dennis Cooper em voz off, que ele ouve, e a música obsessiva de Peter Rehberg. A forma de cooperação narrativa induzida por este espectáculo aproxima-se, portanto, da que Alain Robbe-Grillet, no início dos anos 60, exigia do seu leitor:

Este presente que se inventa incessantemente, como que no fio da escrita, que se repete, se desdobra, se altera, se desmente, sem nunca se organizar para formar um passado - portanto, uma "história" no sentido tradicional -, tudo isso só pode convidar o leitor (ou espectador) a um modo de participação diferente daquele a que estava acostumado. [...] Pois, longe de o negligenciar, o autor hoje proclama a absoluta necessidade da sua cooperação activa, consciente, "criadora". 0 que ele the pede, já não é receber um mundo completo, cheio, fechado sobre si mesmo, mas, pelo contrário, participar ele próprio numa criação, de inventar, por sua vez, a obra - e o mundo - e de aprender, assim, a inventar a sua própria vida. (Ibid.: 134)

\section{Referências bibliográficas}

ROBBE-GRILLET, Alain (1963), Pour un nouveau roman, Paris, Les Éditions de Minuit.

LEHMANN, Hans-Thies (2002), Le théâtre postdramatique, Paris, L'Arche.

Tradução de Sebastiana Fadda 